\title{
Gênero e planejamento familiar: uma abordagem ética sobre o compromisso profissional para a integração do homem
}

Gender and family planning: an ethical approach about the professional commitment toward the integration of men

Género y planificación familiar: un enfoque ético en el compromiso profesional para la integración del hombre

\author{
Marta Sauthier', Maria da Luz Barbosa Gomes' \\ ' Universidade Federal do Rio de Janeiro. Escola de Enfermagem Anna Nery. Rio de Janeiro-RJ, Brasil.
}

Submissão: 06/02/2010 Aprovação: 07/09/2010

\section{RESUMO}

Os objetivos do estudo constituíram-se em caracterizar as atividades desenvolvidas pelos profissionais de saúde, especialmente os(as) enfermeiros(as), na execução do Programa de Planejamento Familiar; analisar a conduta dos profissionais de saúde quanto à integração do homem nessas atividades e discutir a dimensão ética dessa conduta para a integração do homem no programa. A abordagem metodológica é qualitativa, o estudo é descritivo e o método dialético com utilização da análise do discurso. Foram depoentes nove profissionais da saúde nos cenários da rede pública. Observou-se que a política de trazer o homem para o centro das discussões nos grupos de Planejamento Familiar existe na proposta do Programa, mas, na prática, é falha. Os(a) enfermeiros(as) e assistentes sociais, na ação educativa, convivem com limites e possibilidades e, quanto mais vivenciam essa tensão dialética, mais estarão preparados(as) para superar essas situações de difícil solução.

Descritores: Enfermagem; Planejamento familiar; Ética.

\section{ABSTRACT}

The objectives of the study were to characterize the activities developed by the health professionals, especially the nurses, in the performance of the family planning program; to analyze health professional's behavior concerning integration of men in these activities and, to discuss the ethical dimension of the behavior toward the integration of men in the Program. The methodological approach was qualitative, the study is descriptive and the method is dialectic, using the discourse analysis. Nine health professionals, included in the public health scenery, have participated in the study. It was observed that the policy of bringing men to the center of discussion in the Family Planning groups is patent in the Program proposal, but, in practice, is a failure. The nurses and social assistants, during the educational performance, live with limits and possibilities and, the more they live that dialectic tension, the more they will be prepared to overcome those situations of difficult solution.

Key words: Nursing; Family planning; Ethics.

\section{RESUMEN}

Los objetivos del estudio consistieron en caracterizar las actividades realizadas por profesionales de la salud, sobre todo enfermeros(as), en la ejecución del Programa de Planificación Familiar; examinar la conducta de los profesionales de la salud que incorporen el hombre en estas actividades; y discutir la dimensión ética de esta conducta para la integración del hombre en el Programa. El enfoque metodológico fue cualitativo; el estudio es descriptivo y el método es dialéctico, con uso de la análisis del discurso. Participaran del estudio nueve entrevistados, profesionales de la salud en los escenarios de la red pública de la ciudad de Río de Janeiro. Fue observado que la política de traer el hombre al centro de las discusiones en grupos de Planificación de la Familia existe en la propuesta del Programa, pero, en la práctica, es falla. Las enfermeras y trabajadores sociales, en las actividades educativas, viven con los límites y posibilidades, y cuanto mayor la experiencia de esta tensión dialéctica, más estarán dispuestos a superar situaciones difíciles de resolver.

Palabras clave: Enfermería; Planificación de la Familia; Ética. 


\section{INTRODUÇÃO}

O Planejamento Familiar, implementado oficialmente em 1984, é um Programa que leva em consideração a liberdade do casal em decidir o número de filhos que podem ou querem ter. Deve ser realizado com a consciência de gênero, incluindo o homem em suas atividades e compreendendo a posição da mulher na sociedade; identificando a ideologia que permeia o programa, contribuindo na educação sexual e saúde reprodutiva, com ênfase na prevenção de Doenças Sexualmente Transmissíveis ${ }^{(1)}$.

Atentarmos para os discursos e ideologias que os profissionais enfermeiros e equipe multidisciplinar realizam na educação em saúde, como os discursos controlistas, que se diferenciam do discurso proposto pelo Programa de Planejamento Familiar, que se faz necessário, se buscamos uma conduta ética em saúde.

O Planejamento Familiar constitui uma das ações de saúde preconizadas pelo Programa de Atenção Integral à Saúde da Mulher (PAISM). No Manual do Coordenador de Grupos de Planejamento Familiar, do Ministério da Saúde ${ }^{(2)}$, encontra-se que o componente de anticoncepção deverá ser executado dentro de princípios éticos e de saúde, garantindo a livre opção das pessoas na escolha do método anticonceptivo mais adequado.

A prática anticoncepcional foi se caracterizando como uma responsabilidade feminina, já que os papéis sexuais dos homens e das mulheres são diferentes na nossa sociedade. E, mesmo as mulheres trabalhando fora, estando mais informadas, modificando seus valores, ainda enfrentam o conflito entre a vivência atual e a educação que receberam. Desta forma, a prática da contracepção permanece, na maioria das vezes, ambígua, culposa e angustiada ${ }^{(2)}$.

O planejamento familiar, como política social e demográfica, incide sobre as esferas da saúde, educação e promoção social e tem sido hoje, no Brasil, uma formulação estatal ${ }^{(3)}$. Há controvérsias e ambigüidades que acompanham este programa.

De 1974 a 1983, surge o Planejamento Familiar no Brasil, que faz parte do PAISM, implantado sob cuidadosa estratégia política, contando com dois grupos aliados, a Igreja Católica e o Movimento de Mulheres e grupos a imobilizar "os inimigos": os controlistas e neomalthusianos. Constituiu-se no primeiro programa nacional e oficial que contemplou o Planejamento Familiar no Brasil, e está, na prática, nestas últimas décadas, funcionando precariamente, reflexo dos serviços públicos de assistência à saúde, de uma maneira geral, cuja deficiência crônica se faz cada vez mais evidente e grave ${ }^{(4)}$.

A Sociedade Civil de Bem-Estar Familiar no Brasil (BEMFAM), numa linha neomalthusiana, define Planejamento Familiar como

o exercício da Paternidade Responsável, a utilização, voluntária e consciente, por parte do casal, do instrumento necessário à planificação do número de filhos e espaçamento entre uma gestação e outra, pressupõe o uso dos métodos anticoncepcionais produzidos pela moderna ciência médica. A Paternidade Responsável não pode ser alcançada sem a efetivação do Planejamento Familiar. Não basta apenas educar e conscientizar os casais: é preciso, também, dar acesso aos meios indispensáveis à prática da Paternidade Responsável, principalmente quando se tratarem de populações carentes de recursos ${ }^{(5)}$.

\section{No PAISM, Planejamento Familiar é definido como}

o direito de todos os seguimentos da sociedade à livre escoIha dos padrões de reprodução que lhes convenham como indivíduos ou como casais. Para que esse direito possa ser efetivamente exercido, é necessário que os indivíduos tenham conhecimento das possibilidades de influir no ritmo da procriação e tenham acesso às informações e aos meios para que possa intervir se assim o desejarem, para separar o exercício da sexualidade da função reprodutiva e, em conseqüência, exercer na plenitude o planejamento da sua prole, objetivo complexo, porém, de alcance possível com a implantação e firme execução da proposta de assistência integral à saúde da mulher e o apoio desejado de todos os segmentos da sociedade ${ }^{(5)}$.

A conceituação de Planejamento Familiar, desde o seu início, passando pelos controlistas e antinatalistas, da BEMFAM ao Centro de Pesquisa e Assistência Integrada à Mulher e à Criança (CPAIMC), "Prevenção da Gravidez de Alto Risco", "Paternidade Responsável", até o PAISM, foi distinta, pois houve evolução temporal, histórica, política, bem como, se estruturaram as ações da política de saúde de formas diferentes, em épocas diferentes, com questões éticas e legais em questionamento e com a mudança de pensamento e adesão do Estado, da Igreja Católica, bem como dos grupos feministas ${ }^{(4)}$.

Uma definição, para a década atual, de Planejamento Familiar não pode deixar de ser democrática, que leve em consideração a liberdade do casal em decidir o número de filhos que podem ou querem ter. Mais ainda, que seja realizada com a consciência de gênero, no sentido de se incluir o homem nas atividades e no Programa de Planejamento Familiar e compreender a posição da mulher na sociedade, bem como procurar identificar a ideologia que permeia o Planejamento Familiar, contribuindo com a explanação dos direitos de cidadãos que devem exercer tanto o homem quanto a mulher.

Nessa reflexão, construímos a seguinte questão norteadora deste estudo: Qual a conduta dos profissionais de saúde para a integração do homem nas atividades de planejamento familiar? O objeto constituiu-se no compromisso dos profissionais de saúde, especialmente dos (as) enfermeiros (as), com a integração do homem nas atividades do programa de planejamento familiar, tendo a ética como um de seus fundamentos. Os objetivos foram: caracterizar as atividades desenvolvidas pelos profissionais de saúde, especialmente os (as) enfermeiros (as), na execução do programa de planejamento familiar; analisar a conduta dos profissionais de saúde quanto à integração do homem nessas atividades e discutir a dimensão ética da conduta dos profissionais de saúde para a integração do homem no programa, percebendo essa atitude integradora como um passo para um mundo sustentável, em que pessoas conscientes possam planejar a prole. 


\section{METODOLOGIA}

A pesquisa é descritiva, do tipo qualitativo, pois se preocupa "com um nível de realidade que não pode ser quantificado, ou seja, trabalha com um universo de significados, motivos, aspirações, crenças, valores e atitudes, permeando os fatos, as relações e as estruturas sociais"(6). Estas últimas são tomadas, tanto no seu advento quanto na sua transformação, como construções humanas significativas, dos processos e dos fenômenos que não podem ser reduzidos à operacionalização de variáveis e que auxiliam na descrição e explicação das relações sociais.

No que se refere à pesquisa qualitativa, nenhuma abordagem é suficiente para a compreensão completa da realidade observada. Entretanto, afirma-se que a abordagem qualitativa vê o social como um mundo de significados passível de investigação e a linguagem como matéria prima dessa abordagem, entretanto, algumas vezes, pode contrastar com a prática dos atores sociais ${ }^{(7)}$.

Por outro lado, o estudo é descritivo, pois se busca conhecer melhor, nos profissionais de saúde que atuam em atividades de Planejamento Familiar, os discursos, compromissos, condutas, seu preparo para a integração dos homens no grupo misto, independente da orientação sexual, percebendo-se que a interferência somente será possível se houver uma descrição, "com exatidão" dos fenômenos e fatos da realidade dessas atividades ${ }^{(8)}$.

Utilizou-se a lógica dialética nesta pesquisa, por ser a que melhor responde às necessidades da pesquisa na área da saúde, pois a mesma jamais está desvinculada da pesquisa social que vincula a teoria à prática. A visão dialética privilegia a contradição e o conflito; o fenômeno da transição, da mudança, do vir-a-ser sobre a estabilidade; o movimento histórico; a totalidade e a unidade dos contrários; dialético "é o método do desenvolvimento e da explicação dos fenômenos culturais, partindo da atividade prática e objetiva do homem histórico" ${ }^{\prime(9)}$. O homem histórico constrói sua própria história enquanto cidadão. Esta abordagem é a mais apropriada para este estudo, considerando que a pessoa participa de processos sociais que são dinâmicos, nada é eterno fixo ou absoluto. Não encontramos idéias, instituições e categorias que sejam imutáveis. A vida humana e social está sujeita a mudanças, transformações, por isso, toda a construção social é histórica( ${ }^{(9)}$.

$\mathrm{Na}$ construção do objeto de pesquisa, despertamos para a forma como são percebidas as relações sociais. A sociedade é percebida como construída a partir do processo interativo de indivíduos e grupos que agem em função dos sentidos que o seu mundo circundante representa para eles ${ }^{(10)}$.

Precisamos vislumbrar o homem-sujeito, pautados na autorreflexão, em que se lute pela libertação e humanização do homem e da sociedade, através da conscientização para daí se atingir a transformação social ${ }^{(11)}$. A conscientização não pode existir fora da praxis, sem o ato ação-reflexão, diz também que esta unidade dialética constitui o modo de ser e de transformar o mundo ${ }^{(12)}$.

Desta forma, o método dialético, utilizado nesta pesquisa, é o reflexo da postura que se preconiza para a transformação, a partir da análise crítica dos discursos dos profissionais que atuam no planejamento familiar.
No que se refere ao cenário do estudo, atualmente, as atividades de planejamento familiar são comuns em maternidades públicas e particulares, onde há o programa de pré-natal, em Postos de Saúde e em Centros Municipais de Saúde. Convém destacar que nem todos os Centros Municipais de Saúde desenvolvem efetivamente atividades no planejamento familiar. As unidades de saúde selecionadas foram: Centros Municipais de Saúde (CMS) Marcolino Candau (Cidade Nova) e Ernesto Zeferino Timbau (São Cristóvão) e no Hospital Universitário Gaffrée e Guinle (Tijuca), onde há essa prática, constante no Programa de Assistência Integral à Saúde da Mulher (PAISM). A escolha destas Unidades de Saúde (cenários deste estudo) justifica-se pela facilidade da coleta de dados, uma vez que, em uma das unidades, uma das autoras deste estudo realizou a coleta de dados de sua dissertação de mestrado; e as duas outras unidades são campos de estágio, onde atuava.

Os atores sociais, totalizando nove depoentes, foram profissionais da área da saúde que atuam na ação educativa em atividades de planejamento familiar, e sua seleção obedeceu aos seguintes critérios. Critérios de inclusão: ser profissional da área de saúde ou afim; trabalhar com a população na ação educativa do planejamento familiar (efetivamente), pois, apenas quem atua com os grupos pode incluir, integrar e educar homens e mulheres nos grupos de PPF. Critério de exclusão: Profissionais que apenas assinam como responsáveis pelo programa, atuando apenas na colocação do DIU, ou em qualquer outra atividade, como distribuir os meios contraceptivos, sem atuar nas palestras de planejamento familiar na ação educativa, pois não estará atuando com o grupo, impedido, assim, de promover a integração do homem nas palestras de PPF.

As entrevistadas foram quatro enfermeiras (sendo duas docentes que atuavam com os alunos nas instituições), um residente de enfermagem, um estagiário de enfermagem, uma técnica de enfermagem e dois assistentes sociais, que atuavam há mais de um ano no PPF. Utilizamos um código para identificação dos depoentes: $\mathbf{D}$ e número arábico (para os depoentes); Letras A, B ou C (para as instituições) e $\mathbf{E}$ (para enfermeira); AS (para assistente social); TE (para técnica de enfermagem); RE (para residente de enfermagem) e EE (para estagiário de enfermagem).

Os dados foram coletados por entrevistas gravadas e transcritas, utilizando-se um roteiro semiestruturado, aplicado a partir de perguntas abertas, servindo de eixo para a condução das mesmas. Posteriormente, os dados foram codificados, classificados e indexados no computador. Para a indexação, criamos arquivos conceituais, que foram separados por temáticas e unidades de análise. As relações no âmbito dos dados foram identificadas pela ocorrência, coocorrência e estabelecimento de relação entre as classes.

A análise preliminar e a classificação dos dados foram realizadas de forma concomitante à coleta. A fase mais formal foi efetuada quando encerramos a coleta de dados. Nessa fase, com a idéia mais clara das possíveis direções teóricas do estudo, o material foi trabalhado. Para cada tema emergente, utilizamos o referencial pertinente, com ênfase nos conceitos teóricos de Paulo Freire, considerando a dimensão ética, social, política e econômica que permeiam o fato estudado. 
A análise do discurso, que se buscou aqui, teve a pretensão de captar um sentido oculto no discurso, o qual, sem técnica apropriada, permanece inatingível ${ }^{(14)}$.

Desta forma, essa análise pressupõe o discurso: no quadro de instituições que restringem fortemente a enunciação; onde se cristalizam conflitos históricos, sociais, que determinam o espaço próprio no exterior de um interdiscurso limitado. Como exemplo, o discurso limitado pela construção social de gênero, dado o patriarcalismo que incutiu conceitos e preconceitos entre os gêneros; ou pelo discurso controlista de uma política de saúde anterior aos nossos tempos; ou ainda, por interferência de fenômenos como a globalização, trazendo ideologias, das quais nem sempre se tem consciência.

A validação dos dados deu-se a partir da leitura da análise por três depoentes e duas pessoas familiarizadas com o ato de pesquisa.

Os aspectos éticos da pesquisa obedeceram a Resolução 196/96 do Conselho Nacional de Saúde (CNS). O projeto foi submetido ao Comitê de Ética do Município do Rio de Janeiro, que aprovou, sem restrições, a realização da pesquisa, conforme Memorando $n^{\circ} 25$, de 15 de novembro de 2003. Todas as depoentes forneceram a autorização escrita para utilização dos depoimentos no estudo, mediante o termo de consentimento livre e esclarecido. Além da ciência sobre o objeto, os objetivos, a justificativa do estudo e da tese a ser defendida, cada depoente recebeu a garantia sobre seu anonimato.

Os resultados apontaram para duas grandes categorias e quatro subcategorias.

\section{RESULTADOS ANALISADOS}

\section{Categoria 1 - O Programa de Planejamento Familiar (PPF)}

Subcategoria 1a - Composição das equipes que atuam no PPF e formação profissional ou capacitação

Buscamos caracterizar, no campo da prática, o Programa de Planejamento Familiar (PPF) operacionalizado nos Centros Municipais de Saúde (CMS) e no Hospital Universitário (HU), estudados.

O Programa de Planejamento Familiar é dever do Estado que, pelo Sistema Único de Saúde, promoverá o treinamento de recursos humanos visando a saúde reprodutiva ${ }^{(1)}$. Qualquer profissional da área da saúde ou afim pode atuar na atividade educativa do PPF: enfermeiro(a); médico(a); assistente social; sociólogo(a); auxiliar de enfermagem, entre outros ${ }^{(2)}$. Basta que o profissional esteja motivado e sensibilizado com as questões que envolvem a saúde integral da clientela.

Os dados nos mostram que a equipe multidisciplinar está capacitada pela Secretaria Municipal de Saúde (SMS) para atuar nas atividades de Planejamento Familiar, mas, efetivamente atuando com os grupos, encontramos basicamente técnicas de enfermagem; enfermeiras; assistentes sociais e estagiários e residentes de enfermagem.

Os médicos, psicólogos e nutricionistas recebem os clientes encaminhados para atendimento individualizado, quando apresentam algum problema, ou como rotina, como exemplo, a gestante para a nutricionista. Portanto, há uma compartimentação na estrutura das equipes, nas instituições estudadas. Pois eles não atuam em conjunto na ação educativa do PPF. Uma depoente defende o conjunto de profissionais habilitados para a ação educativa referida.

Equivocadamente, como você fazer grupo para educação em saúde não prescindisse de conhecimento de anatomia, fisiologia, de algumas ciências sociais, porque você não trabalha com a sociedade com uma formação de nível médio. Isso é um equívoco. Só se trabalha razoavelmente tendo uma assistente social no grupo, que faz um trabalho diferente do meu, mas que se complementa e teria uma psicóloga no grupo. Quer dizer, é o conjunto desses profissionais que faz com que o trabalho tenha qualidade. (D7 $-B-E)$

Se a depoente percebe que o conjunto dos profissionais dá qualidade ao serviço, é importante ser destacada a assertiva de Freire ${ }^{(17)}$, segundo a qual não devemos nos julgar como habitantes de um mundo estranho, de técnicos e especialistas salvadores dos demais, donos da verdade e do saber que devem ser doados aos "ignorantes" e incapazes". Por outro lado, seguindo na medida em que o compromisso não pode ser um ato passivo, implica em um conhecimento da realidade. Se o compromisso só é válido se carregado de humanismo, este só é conseqüente se fundado cientificamente. Daí a exigência de um constante aperfeiçoamento, substituindo a visão ingênua por uma visão crítica da realidade.

\section{Categoria 2 - O compromisso dos profissionais com a inte- gração do homem no planejamento familiar}

Subcategoria 2a - Fatores sociais, políticos, econômicos e ideológicos que interferem no PPF

O estudo nos mostra que o PPF é uma realidade enquanto proposta, entretanto, na visão dos profissionais de saúde, o poder público não oferece condições para sua implementação.

Porque um programa não nasce assim, não é como uma criança que você resolve adotar [...] Eles criam o programa, fazem nascer o bebê e depois te entregam e dizem te vira, o bebê agora é seu [...] Não tem planejamento [...] Não tem pessoal para avaliar que unidade pode, que unidade não pode, por quê? [...] Esse posto de saúde tem oito enfermeiras.... (D7 $-B-E)$

Esse discurso nos informa a visão da depoente com relação à necessidade de avaliar a disponibilidade de pessoal para implantação do programa, uma vez que uma das diretrizes do Ministério da Saúde ${ }^{(20)}$ é garantir recursos humanos para a efetividade do PPF.

O projeto de lei que regulamenta o planejamento familiar, aprovado pelo Congresso Nacional e sancionado pelo Presidente da República, em 1996, obriga "as instâncias gestoras do SUS, em todos os seus níveis, garantir à mulher, ao homem 
ou ao casal, em toda a sua rede de serviços, a assistência à concepção e contracepção como parte das demais ações que compõem a assistência integral à saúde"(20).

O SUS é a política de uma gestão descentralizada, redefinindo papéis federais, estaduais e municipais ${ }^{(21)}$. São objetivos do SUS a identificação e divulgação dos fatores condicionantes e determinantes da saúde; a formulação de política de saúde destinada a promover, nos campos econômico e social, a observância do dever do Estado em garantir a saúde da população; a assistência às pessoas por intermédio de ações de promoção, proteção e recuperação da saúde, com a realização integrada de ações assistenciais e atividades preventivas.

Assim, cabe às instâncias gestoras redistribuir ou contratar pessoal para implementar os programas que são decretados por lei. Dentre eles, o PPF, que encontra entraves para sua realização. A falta de contratação de pessoal é um paradoxo com a demanda, bem como, com as ações e programas de saúde implementados.

A gente parou de fazer planejamento, discussão de meta, a saúde pública elaborada com avaliação ela foi morta nos últimos 10 anos. [...] Fazemos pronto atendimento para registrar números, atender pessoas, independente de resolver ou não os problemas dessas pessoas. E você não trabalha o problema de saúde pública dessas pessoas, você não tem previsão, planejamento, estratégia pactuada na instituição e as coisas vão acontecendo desordenadamente, certo? (D7 - B -E)

A consciência de falta de compromisso dos governantes com a Política de Saúde que garanta os direitos constitucionais dos cidadãos, trazendo a contradição entre o que preconiza o PPF e o seu funcionamento nas unidades de saúde é explicitada na fala. Quanto à organização dos serviços, uma das condições para sua efetividade é garantir a avaliação das ações da assistência ao PF(20). E tem como objetivos: avaliar a qualidade da assistência; identificar os problemas de saúde da população-alvo e do desempenho do serviço; permitir a mudança de estratégias com a finalidade de melhorar a assistência ao PF.

Nesse sentido, o próprio programa entra em contradição ao utilizar a estatística da percentagem de mulheres atendidas e que retornaram ao local de referência, não criando avaliação qualitativa. Além disso, não inclui, na avaliação, o atendimento aos homens. Essa contradição contribui para a dificuldade de inclusão e integração do homem no PPF, bem como para que se faça uma avaliação da assistência prestada, pois, quanto à política de inclusão do homem nas atividades do Programa de Planejamento Familiar, encontramos:

Mais das mulheres, os homens são muito raros [...] (D6 $B-A S)$

[...] tem que ter uma política implementada nesse sentido, que atualmente está muito tímida, e foi implementada em 91, quando a gente começou o desenvolvimento com os profissionais da rede, mas que começou muito tímida... (D9 - C - AS)
Nesses discursos, observamos que a política de trazer o homem para o centro das discussões nos grupos de planejamento familiar, existe na proposta do P.P.F., mas, na efetividade, é falho. Constatamos a necessidade de uma ação coletiva para a decisão, para a responsabilidade social e política de integração do homem no P.P.F. por meio da deliberação coletiva onde se revejam valores, à luz do consentimento e compreensão intelectual. Isso só será possível através de um método ativo, dialogal, participativo e, conseqüentemente, ético.

Conforme a Conferência Internacional sobre População e Desenvolvimento, realizada em 1994, no seu parágrafo 4.27, a questão ética da responsabilidade do homem na promoção e efetivo envolvimento com relação à paternidade responsável, comportamento sexual e reprodutivo, principalmente nos casos de gravidez não planejada e a de risco, são propostas para os governos mundiais, especialmente para os países em que essas ocorrências são maiores, como no caso do Brasil.

O Manual do Coordenador dos Grupos de Planejamento Familiar (1987, p. 5) traz opções didáticas para trabalhar os grupos e refere que cada comunidade tem suas especificidades, cabendo a adaptação das atividades educativas serem realizadas pelos profissionais. E ainda, expõe que o material fornecido pelo M.S. visa "motivar os profissionais a usarem a metodologia sugerida, adaptando, modificando e criando novas técnicas que auxiliem na perseguição dos objetivos do Planejamento Familiar" (2). Mas a realidade é que:

[...] há falta de material educativo, o material educativo nosso é velho, da gente ficar lá com uma boneca de papelão [...] que a gente fica recolando a boneca, remontando. Já tem sete anos que a gente tem aquela boneca de papelão. Uma fita de vídeo doada por um laboratório, o que não é o ideal. [...] no início do programa em que a gente recebeu algum material, depois não teve renovação de mais nada. $(D 7-B-E)$

Vale destacar que o conhecimento dos métodos e livre escolha é uma das ações da política do PAISM, preconizada pelo MS, desde 1984: “conforme os princípios que regem esta política, os serviços devem garantir o acesso aos meios para evitar ou propiciar a gravidez, o acompanhamento clínico-ginecológico e ações educativas para que as escolhas sejam

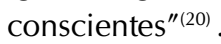

Trabalhar sem recursos, sem renovação de material audiovisual e ampliação de recursos humanos é um altruísmo, mas também é uma atitude que contribui para a falta de responsabilização política e acomodação dos dirigentes. $\mathrm{O}$ assumir desse trabalho, sem contestação frente à falta de recursos, faz com que mais programas sejam assumidos pelos "heróis da rede pública" sem recursos materiais e humanos.

Eu não sou enfermeira só do planejamento familiar, eu tenho mil e tantas mulheres no programa, mais não sei lá quantas gestantes, mais a equipe que eu tenho que supervisionar, as escalas que eu tenho que fazer, o material que eu tenho que prover e mais tudo que qualquer outra enfermeira faz, entendeu? [...] Porque as coisas vão se acumulando [...] a Secretaria mandou um programa de 
acolhimento [...] maravilhoso, a mãe vem da maternidade com um encaminhamento, ela vai ter BCG, teste do pezinho, aproveitando vai ter a primeira consulta de Puericultura, retiradas de pontos, vai ter tudo [...] E aí, eu pergunto: quem vai fazer? Qualquer coisa depende de gente. Eu acho que a gente é malabarista, porque não sei como é que está sendo [...] (D7 - B -E)

Quanto aos fatores ideológicos, em toda sociedade existem as ideias dominantes; dessa forma, as relações, a produção e a organização social não esgotam os fatores que influem na realização da moral. A tradição e os costumes impõem uma regra moral, sem que as pessoas examinem a sua natureza e conseqüências. As pessoas não estão privadas por completo de decidir sobre si mesmas, mas sofrem a influência da família, de organizações sociais, da escola e da igreja.

As diferenças ideológicas entre o feminismo, a igreja conservadora e o Estado estão expressas no alerta que as feministas fazem de que o governo federal deve tomar cuidado para não transformar a conscientização sobre PF em algo impositivo e compulsório.

Os representantes mais ortodoxos das igrejas, por sua vez, são contra a liberdade reprodutiva, continuam ideologicamente natalistas. Assim, são contra todos os métodos contraceptivos não naturais. Consideramos que a igreja não tem o direito de impor uma regra natalista a todas as mulheres e homens do mundo, o que é reforçado por integrantes da Igreja Católica, mais coerentes com a realidade socioeconômica na qual vivemos (21). Dizem eles que "os métodos radicais são 'um mal menor' ou quem sabe 'um bem maior'".

A opção pela reprodução deve ser uma atitude responsável e consciente e, ainda, partilhada pelo casal. A realidade socioeconômica sugere famílias de pequeno porte, mais adequadas ao orçamento familiar e as atividades da mulher e do homem no mercado de trabalho.

Para nós, a prática do PF é benéfica para a família e para a sociedade. Cabe ao Estado oferecer os meios e as informações para ambos, homens e mulheres, assumi-lo de forma responsável na construção de uma família.

Subcategoria $2 b$ - A construção de gênero e a integração do homem no PPF

O aprofundamento sobre as questões de gênero, as quais serviram como pano de fundo para esse estudo, merecem maior reflexão, uma vez que interferem na conduta do profissional na integração do homem nas atividades do planejamento familiar.

Demonstramos, até aqui, que compreendemos gênero como papéis, atributos e atitudes que definem o feminino e o masculino em nossa sociedade. Embora não esteja em lei escrita, essas regras são apreendidas e, por serem construídas pelos homens, podem ser remodeladas com a evolução social. O fato é que essas relações de gênero são desiguais e refletem-se nas leis, condutas profissionais e nas relações entre os seres humanos.

São vários os fatores contribuintes para que o homem não se integre, ou deixe de ser integrado, nos grupos de Planejamento Familiar, mas todos esses fatores passam pelo viés da construção social de gênero.
No que se refere a gênero, o termo é definido em duas partes e diversas subpartes, ligadas entre si, mas que deveriam ser distinguidas na análise ${ }^{(22)}$. O núcleo essencial da definição repousa sobre a relação fundamental entre duas proposições: "o gênero é um elemento constitutivo de relações sociais fundadas sobre as diferenças percebidas entre os sexos, e o gênero é um primeiro modo de dar significado às relações de poder"(22).

A organização dos grupos, para atividades educativas, encontra dificuldade quanto à construção social de gênero que está cristalizada na memória dos profissionais e população, algumas vezes se opondo à participação do homem nos grupos, ou colocando a mulher em lugar de submissão.

A gente fala assim para elas: 'vocês vão ler para eles a cartiIha para decidir pelo melhor método. Mas o corpo é de vocês, então a decisão que tem que pegar mais é a de vocês'. Tem até muitos homens que não querem que a mulher use o DIU porque acham que vai arranhar. Mas a gente diz: 'afinal a decisão final tem que ser sua' [...] (D6, AS, B)

Embora o conceito de gênero seja conhecido pelos profissionais, sua assimilação, neste discurso apresentado, é falha. O discurso veicula, nem sempre de forma consciente, as marcas da nossa cultura, nossos pensamentos e ideologia. Quanto às questões que envolvem gênero: ao afirmar que, para o homem interessa assuntos específicos do PPF, como o uso do método de barreira, o profissional o "exclui" da integração com o grupo, já que, para ele, não é importante outros assuntos ali abordados. Separar assuntos de homem de assuntos de mulher, no PPF, é uma atitude que cristaliza preconceitos.

Neste depoimento, ao tentar informar que a mulher "evoluiu" na sociedade, reafirma o discurso da dominação masculina:

A mulher evoluiu na sociedade. A gente mostra pra elas que têm mulheres motoristas de ônibus ... (D6, B, AS)

Quando, para expressar essa "evolução", exemplifica o assumir de uma função antes considerada apenas masculina, ou seja, a valorização das funções masculinas, representada no termo "evoluiu", embora queira valorizar uma conquista da mulher na sociedade, desvaloriza as atividades ditas femininas.

A igualdade de gênero não está em se assumir funções masculinas, "ideologicamente tidas por superiores", ou ainda, no plano físico, melhor remuneradas; a igualdade está na valorização do que é feminino tanto do que é masculino ${ }^{(23)}$. Assim é que os discursos terminam por reforçar as diferenças entre os gêneros, no lugar de transformar conceitos e ideologias cristalizam tais conceitos.

Os profissionais, ao terem ciência de que a responsabilidade na esfera da saúde reprodutiva é tanto das mulheres quanto dos homens, estarão promovendo a equidade de gênero e estimulando uma nova forma de participação dessa população na transformação social, pois tanto mulheres quanto homens são seres inacabados. O inacabamento de que nos tornamos conscientes nos fez seres éticos ${ }^{(13)}$. $\mathrm{O}$ respeito à autonomia e à 
dignidade de cada um é imperativo ético e não um favor que podemos ou não conceder uns aos outros. Assim, consideramos ética a conduta de integração do homem nas palestras do PPF, bem como o discurso que favoreça a igualdade de oportunidades entre os gêneros.

Subcategoria 2c - O compromisso ético dos profissionais com o Planejamento Familiar

O Programa de Planejamento Familiar requer profissionais comprometidos com sua filosofia, como a de incluir e integrar os homens nos grupos de PF e de atuar com o conhecimento e vivência dos clientes, deixando de agir como detentores de todo o saber ${ }^{(2)}$.

Paulo Freire afirma que "a primeira condição para que um ser possa assumir um ato comprometido está em ser capaz de agir e refletir". Refere também que, somente um ser que é capaz de sair de seu contexto, de percebê-lo de fora, ou seja, "diferenciar-se dele para ficar com ele; capaz de admirá-lo para, objetivando-o, transformá-lo e, transformando-o, saber-se transformado pela própria criação; um ser que é e está sendo no tempo que é o seu, um ser histórico, é capaz, por tudo isso, de comprometer-se"(19).

Os dados nos mostram que os profissionais envolvidos com o PF afirmam que há falta desse espaço de reflexão para a transformação nas palestras de planejamento familiar, ou mesmo para avaliação de sua concretude.

Nós não somos chamados nunca para fazer uma discussão sobre esse programa. Não tem nenhum encontro, não tem nada. É aquela coisa assim, vai tocando aí do jeito que vocês quiserem. Parece aquela expressão que eu uso muito assim, "pra quem é bacalhau basta" [...] é para o povo, então pode ser qualquer coisa. (D7 - B -E)

Numa primeira leitura deste depoimento podemos inferir que a profissional encontra-se, "impedida de comprometer-se" (19), no sentido de que, o espaço para rediscutir a implementação, ou seja, o espaço para "ação-reflexão"(19), que faz do profissional um ser comprometido, não existe e, em não existindo, frustra esse profissional.

Entretanto, aprofundando esta análise, percebemos no discurso da entrevistada uma reflexão sobre a realidade do Programa, as limitações impostas pelo poder público. Ocorre um obstáculo à criação do "espaço oficial". Entretanto, os profissionais criam espaço para avaliação, inclusive com a comunidade, o que nos leva a crer que os profissionais estão comprometidos com a mudança, com a conduta humanizante.

No tocante à disponibilidade para atender os clientes, evidenciamos o dilema das depoentes que, com seriedade ética, com senso de justiça e de solidariedade, vivenciam plenamente seus limites e suas possibilidades ao assumir o compromisso com o cliente. Para alguns depoentes, a disponibilidade do profissional é que caracteriza o seu compromisso com os clientes.

Isso é compromisso para mim, a pessoa chegar aqui e poder contar com o profissional. (D7 - B - E)
Por outro lado, alguns profissionais encontram-se movidos pelo individualismo, nem sempre se colocando disponível. Esta conduta os torna "falsamente comprometidos" (19).

[...] Até porque as pessoas não se permitem flexibilizar seus horários. E, geralmente, o horário que eu escolhi não foi o horário que a instituição me pediu. Mas eu não abro mão desse horário, é complicado, não é? [...] (D7 - B -E)

O uso da liberdade, a disciplina da vontade, a recusa, a tentação de aceitar passivamente o que é imposto nos forjam como sujeitos éticos, não autoritários, submissos ou permissivos. Assim, estaremos mais preparados para o enfrentamento das situações complexas e difíceis que a vida pessoal e profissional nos impõe.

O compromisso com a prontidão para o atendimento da clientela é um dever profissional. Outro dever é o de trazer à consciência da população o direito aos serviços públicos, como os oferecidos pelas instituições estudadas. Compromisso é, também, buscar o cliente naquela comunidade, seja ela qual for.

E quando eu estou lá com essas mulheres, eu as estimulo a participarem do planejamento familiar. Que no Centro de Saúde tem [...]que elas pertencem àquela unidade de saúde, que elas devem e têm direito de ir até lá, eu estimulo tudo isso. Então eu estou sendo uma célula que está angariando cliente para o planejamento. (D8 - B - E)

Outra depoente informa o seguinte:

E o próprio planejamento familiar é muito restrito, porque ele acontece dentro de uma unidade de saúde e nem sempre é acessível às pessoas[...] (D9 - C - AS)

O compromisso com a ação libertadora é demonstrado na prática da depoente. A depoente defende uma prática que vislumbre a possibilidade de mudar, atuando mais com a família, envolvendo a todos, mulheres, parceiros, adolescentes e até idosos, que necessitam de informações sobre DST, bem como de preservativos para evitá-las. E, ainda, que a atividade educativa do planejamento familiar não é acessível, pois acontece dentro do CMS, não se expandindo para as escolas, trabalho e espaços de lazer.

A pedagogia como prática de liberdade não pode fazer concessão às armadilhas do pragmatismo neoliberal que reduz a prática educativa ao treinamento técnico-científico dos educandos ${ }^{(11)}$.

\section{CONSIDERAÇÕES FINAIS}

Promovendo a consciência dos cidadãos sobre sua condição humana, social, política e econômica é que atingiremos a mudança da desvalorização para a valorização da ação educativa e da própria educação.

O poder da economia globalizada, que fragiliza a sociedade, é reconhecido. E só em nome da ética é possível explicar a luta política da ética universal do ser humano, em nome da 
necessária transformação da sociedade na busca da superação das injustiças desumanizantes.

Creditamos às lutas sociais, que convulsionaram a sociedade, a possibilidade que hoje temos de ação-reflexão, de contestação da opressão e da esperança de produzir uma nova visão de mundo. Procuramos a herança histórica e os fatos que deram origem à exclusão do homem do PPF e a responsabilização da mulher. Discutimos o compromisso dos profissionais envolvidos com o Programa, na inclusão do homem, a opressão, as contradições e as lutas diárias para a sua implementação.

Esses poucos "heróis" do serviço público dão testemunho de sua indignação com as condições de trabalho, dando, em resposta, a tenacidade no fazer. Por vezes, melhor seria a contestação, como um dado de libertação e como forma de transformação social, dando uma nova dimensão ética ao compromisso dos profissionais de saúde com a integração do homem no Planejamento Familiar.

A política de trazer o homem para o centro das discussões nos grupos de PPF existe na proposta do programa, mas, na prática, é falha. Atualmente, o programa do planejamento familiar encontra-se implementado como ação educativa e clínica nas instituições estudadas, sendo a ação educativa realizada por enfermeiras e assistentes sociais. O compromisso com uma ação libertadora é demonstrado por aqueles que vislumbram a possibilidade de mudar, atuando mais com a família, envolvendo parceiros, mulheres, adolescentes e até idosos, que atuam como multiplicadores das informações. Alguns profissionais de saúde, envolvidos com a ação educativa, não reconhecem a diferença entre inclusão e integração, na medida em que trabalham para o grupo, mais do que com o grupo.

As enfermeiras e assistentes sociais atuam na ação educativa, convivem com limites e possibilidades e, quanto mais vivenciam essa tensão dialética, mais estarão preparadas para superar essas situações de difícil solução, em favor da justiça e da ética. A integração desse homem é uma questão que exige o compromisso de todos: Estado, família, escola, grupos e sociedade para um mundo melhor e sustentável.

\section{REFERÊNCIAS}

1. Brasil. Ministério da Saúde. Assistência integral à saúde da mulher: bases de ação programática. Brasília: Centro de Documentação do Ministério da Saúde; 1984.

2. Brasil. Ministério da Saúde. Manual do Coordenador de Grupos de Planejamento Familiar. Brasília: Secretaria Nacional de Programas Especiais de Saúde. Divisão Nacional de Saúde Materno-Infantil. Programa de Assistência Integral à Saúde da Mulher; 1987.

3. Canesqui AM. A implantação e expansão dos serviços de planejamento familiar: questões e controvérsias. Rev Paul Enf. 1996;5(1):26-30.

4. Fonseca Sobrinho D. Estado e população: uma história do Planejamento Familiar no Brasil. Rio de Janeiro: Rosa dos Tempos / FNUAP; 1993.

5. Xavier IM. O enfermeiro nos Programas de Planejamento Familiar: aspectos políticos e pragmáticos a serem observados. [Dissertação de Mestrado] Rio de Janeiro: Escola de Enfermagem Alfredo Pinto, UNIRIO; 1988.

6. Minayo MCS. O desafio do conhecimento: pesquisa qualitativa em saúde. 6ed. São Paulo: Hucitec-Abrasco; 1994.

7. Minayo MC, Sanches F. Quantitativo-qualitativo: oposição ou complementaridade? Cad Saúde Públ. 1993;9(3):239-262.

8. Trivinõs ANS. Introdução à pesquisa em Ciências Sociais: a pesquisa qualitativa em educação. São Paulo: Atlas; 1987.

9. Minayo MC, Deslandes SF. (Org.). Pesquisa social: teoria, método e criatividade. 8ed. Petrópolis: Vozes; 1998.

10. Haguette TMF. Metodologias qualitativas na sociologia. 6ed. Petrópolis: Vozes; 1999.
11. Freire P. Educação como prática da liberdade. 24ed. Rio de Janeiro: Paz e Terra; 2000.

12. Freire P. Conscientização. 3ed. São Paulo: Moraes; 1980.

13. Freire P. Pedagogia da autonomia: saberes necessários à prática educativa. 2ed. Rio de Janeiro: Paz e Terra; 1997.

14. Maingueneau D. Novas tendências em análise do discurso. 3ed. São Paulo: Pontes; 1997.

15. Brasil. Lei $n^{\circ}$ 9263/96. Planejamento Familiar.

16. Galvão AM. A crise da ética: o neoliberalismo como causa de exclusão social. Rio de Janeiro: Vozes; 1997.

17. Freire P. Educação e mudança. 16ed. Rio de Janeiro: Paz e Terra; 1979.

18. Fetter MA. Planejamento familiar: uma visão sociológica. 2004 [citado em 26 jan 2004] Disponível em: http:// www.unifam.com.br/Vopinião_01/htm.

19. Freire P. Educação e mudança. 24ed. Rio de Janeiro: Paz e Terra, 2001.

20. Brasil. Ministério da Saúde. Secretaria de Política de Saúde. Área Técnica de Saúde da Mulher. Assistência em planejamento familiar: manual técnico. 4ed. Brasília: Ministério da Saúde; 2002.

21. Pessini L, Barchifontaine CP. Problemas atuais de bioética. 4ed. São Paulo: Edições Loyola / Faculdades Integradas São Camilo; 1997.

22. Scott J. Gênero: uma categoria útil de análise histórica. Educação \& Realidade. 1990;20(2):71-99.

23. Eisler R. O prazer sagrado: sexo, mito e política do corpo. Rio de Janeiro: Rocco; 1996. 